\title{
The social issues of smart home: a review of four European cities' experiences
}

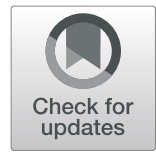

\author{
Saeid Pira(D)
}

\begin{abstract}
The urban industrialization trend and the increasing urban population have posed global and local concerns related to urban management. Today, scientists introduce the "smart city" concept, among many others. The primary concept purpose is to empower cities to enhance the quality of life of their residents. To achieve this, one of the smart city components named "smart living" has a direct connection to citizens' quality of life. This research aims to analyze the smart home as one of the sub-components of smart living. Consequently, based on the "smart home" residents' viewpoint, the main question is which social barriers are more critical?

To achieve this essay's objectives, the researcher conducts three phases: data collection, analysis based on the constructed conceptual model, and results. The researcher selected four leading smart cities in Europe, including Copenhagen, Berlin, London, and Barcelona, as case studies. The study collected primary data by cluster-random sampling by utilizing a questionnaire survey with 320 participants. In conclusion, according to the inhabitants, the research results list the most significant social challenges in smart homes. Eventually, suggestions offer for reducing the side effect of living in a smart home.
\end{abstract}

Keywords: Smart city, Smart home, Smart home technology services, Social barriers

\section{Introduction}

The world has witnessed an increasing accumulation of its people in urban areas since 1990. This trend is not new and represents a substantial increase in urban residents' number, from an approximate average of 57 million between 1990 and 2000 to 77 million between 2010 and 2015 [1]. It poses significant challenges for the environment and social sustainability. Also, the contemporary structure of cities is a source of environmental and social dilemmas. Cities consumed approximately $70 \%$ of the world's resources and are also significant users of energy resources. Hence, they became the main contributors to greenhouse gas (GHG) emissions. The growth of the urban population and the intensity of economic and social activities are triggering this crisis. It is also a consequence of the built environment inefficiency. Current research in urban and academic circles focuses on sustainability in urban planning. Besides, they try to

Correspondence: saeed.piraa@gmail.com

Lund University, Sari, Mazandaran, Islamic Republic of Iran address the main urbanization challenges and the unsustainability of existing structures [2]. The smart cities concept emerged as an appropriate solution to this unprecedented urbanization and the need for sustainability. Therefore, this idea attracted plenty of academic interests in this field [3]. The International Telecommunication Union Focus Group on Smart Sustainable Cities (ITU-T FG-SSC) introduced a definition, which reads as follows: "A Smart Sustainable City is an innovative city that uses Information and Communication Technologies (ICTs) and other means to improve quality of life, the efficiency of urban operation and services, and competitiveness while ensuring that it meets the needs of present and future generations concerning economic, social, environmental as well as cultural aspects" [4]. One of the components of the smart city concept is "smart living." I will explain these criteria in the following sections. The smart home is one of the essential subcomponents of this component, which splits into two sections: (1) state-of-the-art technologies and applications and (2) the behavior of the residents who live in 
these homes. It is crucial to note that city dwellers have contradictory comments about smart home applications. According to the research findings, the way to overcome the social barrier and to communicate with state-of-theart technologies is the key worry of smart home residents. This research aims to find the most concerning social issues for smart homeowners. For this purpose, four European cities (Barcelona, Copenhagen, Berlin, and London) select as case studies. Finally, this study suggests several recommendations to reduce identified social issues.

\section{Literature review}

\section{Smart city}

The idea of smart cities was rooted in the 1970s when a digital configuration based on technology and nonmaterial structures embedded in the urban physical spaces. Afterward, the new aspects of everyday life have been concentrating on more complex innovations. Broadband networks and collective intelligence determining the city development supported these new technologies $[5,6]$. There are different views regarding the origin of the concept of "smart city" in the literature. According to Caragliu et al. (2009), "The city could be smart when investments in human and social resources combined with traditional and modern ICT infrastructures boost sustainable economic growth and high quality of life, with wise natural resource management through participatory governance [7]."

Globalization trends and emerging new technologies are increasingly influencing urban and regional environments. ICTs are also heavily involved in the management and governance of cities. Authorities and planners use these innovations as tools and services to promote the quality of life, promote a sustainable development, and create a more dynamic and innovative urban landscape [7]. Over time, scholars, institutions, and large corporations provide expressions such as digital, smart, ubiquitous, wired, hybrid, information, creative, learning, humane, knowledge, and smart cities. The significant purpose is to describe the renewed configurations adopted within the local context [8].

\section{Smart city definitions}

There are different views regarding the origin of the concept of "smart city" in the literature. According to Garby (2014), the roots of the concept date back to the 1960 s, and in urban development plans, it figures in proposals for networked cities since the 1980s. Also, Dameri and Cocchia (2013) claimed that specialists introduced this concept in 1994 [9]. The roots of this term, according to Neirotti et al. (2014), can be traced back to the late 1990s smart growth trend [10]. That said, it involves growing urban efficiency-related to energy, transport, land use, communication, economic development, service delivery, and so forth. A smart city is an effective strategy focusing on the ICT-based leadership of metropolitan areas [11]. The technological dimension is currently significant in the smart city definition: innovative approaches focused on the Internet network are the basis for a smart city. Besides, the development of a high-quality infrastructure for urban ICT is an integral part of a smart city. Coherent research produced by technology suppliers highlights the importance of this component. Furthermore, it claims that private companies engaged in telecommunications, transport, software, informatics, and electricity are pushing forward the smart city concept [12].

Two of the most relevant concepts will sum up the various variables that define the conceptualization of smart cities:

1. We believe that a city is smart when investments in human and social capital and conventional (transport) and modern (ICT) connectivity networks boost sustainable economic growth and high quality of life through participatory governance, wise management of natural resources.

2. The more recent interest in smart cities can be due to concern for sustainability and the emergence of new Web technologies, such as mobile devices, the semantic internet, cloud computing, and the Internet of Things (IoT), which facilitate the realworld user interfaces [13].

The central point posed by numerous scientists in the smart city concept is the role of ICT in today's cities and the need to enhance emerging technologies. They claim that improving the quality of life of citizens is inevitable without access to these technologies.

\section{Smart city features}

The concept "smart city" is a bit fuzzy since it encompasses a wide range of dimensions and characteristics. According to Nam and Pardo, there are many definitions and considerations relevant to smart cities that contribute to technological, human, and institutional aspects (2011) [14].

Smart cities include the human capital variable as the main element of increasing interest in knowledge-based financial growth and innovation. In addition to being a "new engine" for sustainable development, the involvement of a trained and professional population and workforce is an essential component of this concept. The smart city's employees should be well-trained and creative, with access to other knowledge-sharing opportunities [15-17]. The combination of technical and human dimensions allows for the development of a 
technologically advanced and imaginative network. It is a common strategy to achieve urban development and de-industrialized finance. The utilization of development and social capital through "smart urban communities," composed of firms, education, government, and individuals, depicts the smart city's organization. These communities benefited from ICT and human capital to engage all participants to innovate and beneficially alter the urban environment $[14,18,19]$.

\section{Smart city characteristics}

According to studies, a smart city would have five key components: contemporary technologies, buildings, utilities, transportation, and road infrastructure. In terms of technology, a smart city is a long-term collaboration between government, government institutes, and private companies to develop and implement computerized platforms. This cooperation is concerning with strengthening contemporary technologies, including mobile cloud computing, digital documents, networks, and emerging decision-making methods [20,21].

Smart city notions are as broad as the number of smart cities. Besides the three dimensions explained in Table 1, the following six characteristics should include "smart economy," "smart people," "smart governance," "smart mobility," "smart environment," and "smart living" Those three dimensions influence the outcomes of the six characteristics. Table 2 shows the theories and the characteristics of each of these six characteristics [14]:

Smart living is one of the characteristics of the smart city, according to the table, and the crucial purpose of this component is to boost citizens' quality of life. There are also other aspects of smart living, such as education, safety, and social cohesion.

\section{Smart home}

As stated, the primary goal of smart cities-especially smart living component-is to improve the quality of life of citizens. In this regard, one of the practical

Table 1 Dimensions, concept, and factors of "smart city" [14]

\begin{tabular}{lll}
\hline Dimensions & Concepts & Factors \\
\hline Technological & Digital city & Physical infrastructure \\
& Intelligent city & Smart technologies \\
& Ubiquitous city & Mobile technologies \\
& Wired city & Virtual technologies \\
& Hybrid city & Digital technologies \\
Information city & \\
& Creative city & Human infrastructure \\
Human & Learning city & Social capital \\
& Humane city & \\
& Knowledge city & \\
Institutional & Smart community & Governance \\
& Smart growth & Policy \\
& & Regulations \\
\hline
\end{tabular}

recommendations for achieving smart living is the idea of smart homes. One of the realistic alternatives to implementing smart living is the "smart home" idea. Its principal goal is to combine system, service, and management to provide people with an efficient, comfortable, safe, accessible, and environmentally friendly living environment.

\section{Smart home definitions}

Scientists used multiple notions to describe and conceptualize smart homes (Table 3). Among various approaches, the definition by Aldrich (2003) and Lutolf (1992) dealt inclusively with the nature of smart homes. A smart home, according to Aldrich (2003), is "a house designed with computer and information technologies that anticipates and responds to the needs of the inhabitants, functioning to facilitate their comfort, ease, security, and entertainment through the management of home technologies and connecting to the world beyond." This definition encompasses the phenomenon's technical component, as well as the services and functionality it provides. It is worth noting that smart homes would respond to a wide range of attitudes [23]. Besides, Lutolf (1992) described a smart home as "integrating various facilities through the use of a communication scheme in a home. It ensures an economical, safe, and comfortable home operation and involves a high level of smart functionality and flexibility." [24] Although the two definitions share similar viewpoints, they differ in terms of the technology's capabilities and the types of customers it seeks to serve. Many academics associate smart homes with technological features in general [25].

As mentioned above, there are differing views on the idea of the smart home. The author's point of view in this article is closer to the theories of Aldrich and Lutolf. According to these two scientists, the smart home theory is based on the use of ICT and houses equipped with computer and information technologies. Also, the author considers two factors of functionality and flexibility in this article.

_- Smart home types of services:

Researchers used practical analyses to evaluate these home technologies, which would provide a variety of services to residents. The below are some of the smart home's core features:

(1) The smart home has the potential to improve the consumer and power grid relationship. It assists in data collection on power use, energy costs, and an energy use plan establishment. Smart homes also monitor the efficient use of resources and promote family awareness of energy conservation and environmental sustainability. 
Table 2 Smart city characteristics [14]

\begin{tabular}{lll}
\hline Characteristic & Theory & Feature \\
\hline Smart economy & Regional competitiveness & Entrepreneurialism, innovation, International integration \\
Smart people & Human and social capital & Flexibility, creativity, tolerance, qualification level \\
Smart governance & Participation & Transparency, participation in decision-making, quality of political strategies \\
Smart mobility & Transport and ICT economics & Accessibility, ICT availability, modern and sustainable transport systems. \\
Smart environment & Natural resources & Sustainable resource management, natural attractiveness, lack of pollution \\
Smart living & Quality of life & Educational, cultural and health facilities, safety, housing, social cohesion, tourist attractions \\
\hline
\end{tabular}

(2) A smart home can enhance the lifestyle by promoting home security, safety, accessibility, and interactivity.

(3) A smart home could support remote payment.

(4) Smart homes can use a computer, a mobile phone, and a remote network to monitor and connect with the house.

(5) Smart homes consider the real-time meter reading and security service of the water meter, electric energy meter, and gas meter to provide more efficient and high-quality services.

(6) Supporting the "triple networks" industry and providing the ideal smart service [26].

In recent years, numerous scientists have conducted studies on smart home services, functions, and devices, as seen in Table 4 . The majority of the reviewed papers (41 articles) discussed ensuring a comfortable life. After that, most studies related to the monitoring service (31 references). In contrast, fewer articles focus on health therapy and the supportive functions of smart home technology. Only two papers discuss the consultancy service that smart sensors provide [22].

\section{"Smart city" and "smart home" connection}

The connection between smart cities and smart homes requires multiple applications across numerous fields. There is a term that defines this connection unequivocally, and that is "big data" (https://www.smartcity.press/ how-smart-homes-can-connect-smart-cities/). Data generates from multiple sources resulting in the formation of what is currently known as big data. Data sources are ubiquitous around us as smartphones, computers, environmental sensors, cameras, GPS (Geographical Positioning Systems), and even city dwellers. Multiple applications like social media, digital pictures and videos, commercial transactions, advertising applications, games, and many more exacerbated data generation in the past few years $[27,28]$.

Table 3 Definitions and characteristics of smart homes [22]

\begin{tabular}{|c|c|c|c|c|c|c|c|c|c|c|}
\hline \multicolumn{2}{|c|}{$\begin{array}{l}\text { Definition based on a } \\
\text { theme }\end{array}$} & \multirow[t]{2}{*}{$\begin{array}{l}\text { Aldrich } \\
(2003)\end{array}$} & \multirow[t]{2}{*}{$\begin{array}{l}\text { Lutolf } \\
(1992)\end{array}$} & \multirow[t]{2}{*}{$\begin{array}{l}\text { De Silva } \\
\text { et al. (2012) }\end{array}$} & \multirow[t]{2}{*}{$\begin{array}{l}\text { Reinisch } \\
\text { et al., } 2011\end{array}$} & \multirow[t]{2}{*}{$\begin{array}{l}\text { Scott } \\
(2007)\end{array}$} & \multirow{2}{*}{$\begin{array}{l}\text { Balta-Ozkan } \\
(2014)\end{array}$} & \multirow[t]{2}{*}{$\begin{array}{l}\text { Chan et al. } \\
(2008)\end{array}$} & \multirow{2}{*}{$\begin{array}{l}\text { Diegel et al. } \\
(2005)\end{array}$} & \multirow[t]{2}{*}{$\begin{array}{l}\text { Alam et al. } \\
(2012)\end{array}$} \\
\hline Technology & Sensors & & & & & & & & & \\
\hline & Devices & & & & & * & * & & $*$ & * \\
\hline & $\begin{array}{l}\text { Integrated } \\
\text { systems }\end{array}$ & * & * & * & * & * & * & * & & \\
\hline \multirow[t]{4}{*}{ Services } & $\begin{array}{l}\text { Control/ } \\
\text { monitor }\end{array}$ & & & * & $*$ & & * & & $*$ & \\
\hline & $\begin{array}{l}\text { Energy } \\
\text { management }\end{array}$ & * & * & & * & * & & & * & \\
\hline & $\begin{array}{l}\text { Support and } \\
\text { assist }\end{array}$ & & & & & & & * & & * \\
\hline & $\begin{array}{l}\text { Anticipate and } \\
\text { respond }\end{array}$ & * & & & & & & & & \\
\hline \multirow{7}{*}{$\begin{array}{l}\text { Users' } \\
\text { needs }\end{array}$} & Cost-efficiency & & * & & * & * & & * & & \\
\hline & Comfort & * & * & & * & * & & & & \\
\hline & Emotional & * & & & & & & & & \\
\hline & Security & * & * & & & & & & & \\
\hline & Healthcare & & & & * & & & * & & * \\
\hline & Quality of life & * & * & * & $*$ & * & * & $*$ & * & * \\
\hline & Sustainability & & & & * & * & & & & \\
\hline
\end{tabular}




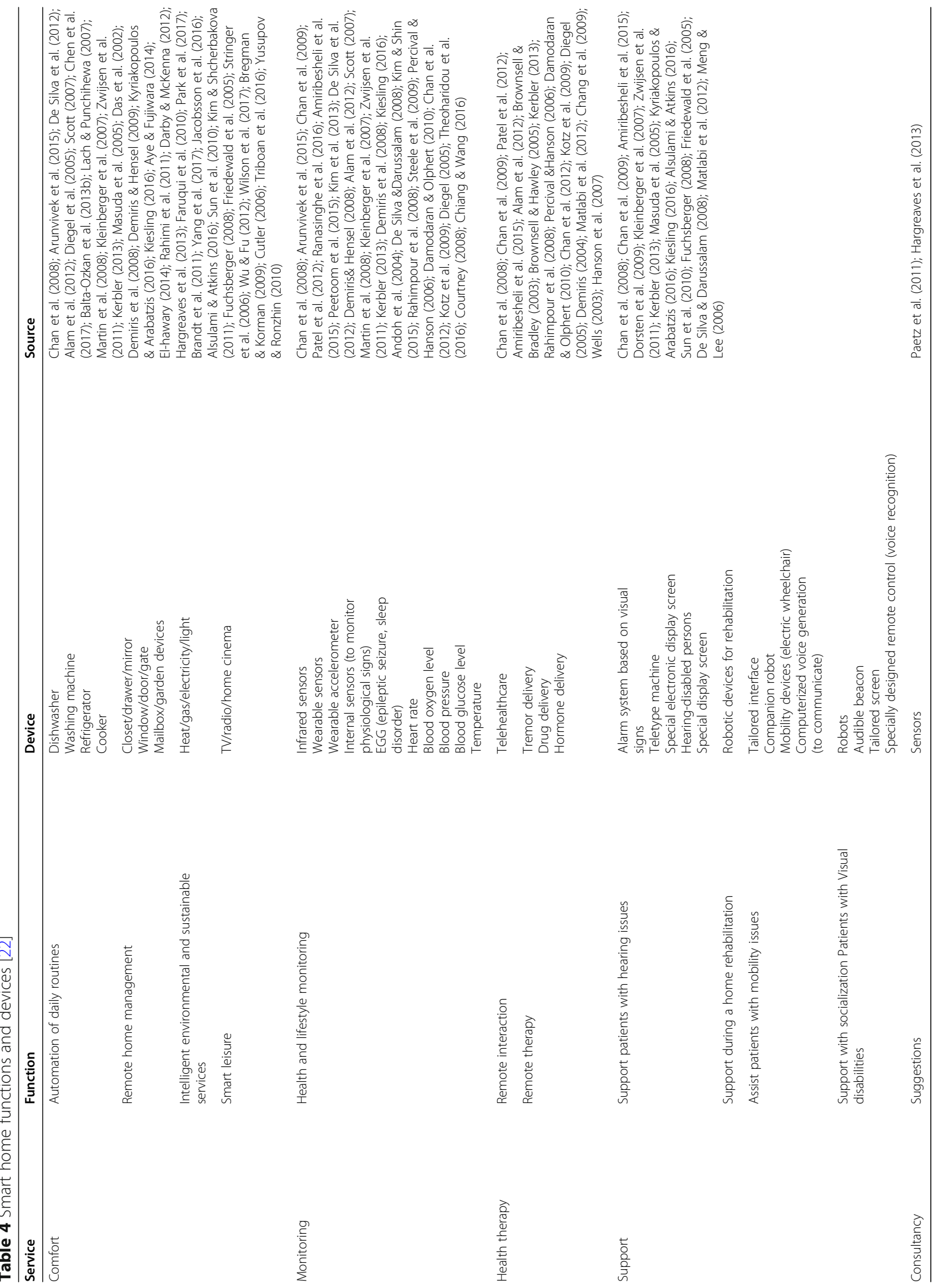


The significance of big data is undeniable. In other words, big data has a critical effect on several aspects of smart cities and, eventually, on citizens' lives [29]. Smart city applications store information, and big data networks utilize this information. Also, big data systems gather information and process it to enhance the multiple services of smart cities. Big data will also help authorities to plan the development of smart city services. There are numerous instances of big data applications that serve the smart cities:

1 Smart education: Through education facilities, ICT offers solutions for improving the quality, efficiency, and profitability of educational systems. These facilities are adaptable in their use of information, better monitoring, and evaluation and expanded learning opportunities for citizens and stakeholders [30].

2 Smart traffic lights: one of the main features of smart cities is effective traffic flow control, which will improve transportation systems and improve the traffic patterns of citizens and the city as a whole [31].

3 Smart Grid: Smart grid is a vital component of smart cities. It is a reconstructed network that gathers and operates on existing data, such as information about suppliers and customers' behaviors, utilizing information, and communication technology in an integrated manner to incorporate values [32].

Smart cities and big data are two modern approaches. Hence, numerous scientists have begun integrating them to develop smart city technologies that will enhance sustainability, improved resilience, efficient government, quality of life, and resource management. Big data applications have the potential to serve many sectors in a smart city. It provides clients improved experiences and lets businesses improve their performance (e.g., higher profits or market share). Also, improve healthcare by improving preventive care services, diagnosis and treatment tools, healthcare records management, and patient care. Big data will significantly help transportation networks to optimize roads, accommodate varying demands, and be more environmentally friendly. Deploying big data applications requires the support of adequate infrastructure for information and communication technology (ICT). Smart cities benefit from ICT since it provides appropriate solutions that would not be available without it [33].

On the other hand, some of the issues that smart cities face while using big data include:

- Data sources and characteristics

- Data and information sharing

- Data quality

- Security and privacy

- Cost

- Smart city population [34]
Some features of the smart city concept related to big data are mention in this section. Consequently, big data is an essential subject in smart cities to support the residents' security, safety, education, and application. These features are part of the smart living sub-components. One of the six characteristics of the smart city conceptwhich includes many features including safety, housing, and education-is smart living. The findings of the study revealed that big data and smart living are inextricably connected.

This research aims to assess the social barriers in smart homes, one of the sub-components of smart living. As reviewed, big data interwove to smart homes and smart cities. Consequently, we can achieve the smart city's established objective by developing big data services.

\section{Pros and cons of smart homes}

Smart homes are one of the EU's ten main fields in the strategic energy technology plan: "Create technologies and services for smart homes that provide smart solutions to energy consumers." The commission aims to promote creative ideas and manage consumers and authorities to optimize their energy consumption (and production). It also enables cities to manage energy usage, relying on smart grid services, through a more interactive/smart system [35].

Smart home technologies (SHTs) incorporate sensors, monitors, interfaces, appliances, and mobile devices to enable household environment automation and remote control. Sensors and monitoring systems control environmental variables like temperature, light, movement, and moisture. Computer applications (smartphones, tablets, laptops, PCs) or specialized hardware interfaces (e.g., wallmounted controls) support the control systems. The main goals, vital advantages, and the most relevant problems of smart homes are listed in Table 5 [36]:

\section{Smart homes' social barriers}

Despite the advantages and disadvantages of new technologies in current urban areas, the use of smart homes is inevitable. We concentrate on the most significant smart home issues in this article. Generally speaking, these problems can divide into two parts: (1) Technological and instrumental concerns and (2) obstacles raised by users of such tools. This paper aims to analyze the challenges of smart homes (especially societal barriers). Table 6 shows the research findings of several articles on this subject.

Multiple social barriers have been found in previous research, according to the table. In this research, a group of urban planners and social scientists looked at these obstacles and divided them into four categories. These components are as follows: 
Table 5 The main features of smart home technologies [36]

\begin{tabular}{ll}
\hline The main purposes & - Managing energy use \\
& - Controlling appliances \\
& - Controlling heating systems \\
& - Making life at home more convenient \\
& - Improving security and safety \\
& - Enhancing entertainment and communication \\
& - Supporting assisted living or health \\
& - Detecting faulty appliances \\
The potential benefits & - Save energy \\
& - Make things less effort \\
& - Save time \\
& - Save money \\
& - Improve security \\
& - Provide comfort \\
& - Provide peace and mind \\
& - Improve the quality of life \\
& - Enhance leisure \\
& - Provide care \\
& - Increase property value \\
& - Increase dependence on technology \\
& - Increase dependence on electricity networks \\
& - Non-essential luxuries \\
& - Increase dependence on outside experts \\
& - Make household members lazy \\
& - Monitor private activities \\
& - Invasion of privacy \\
& - Intrusive \\
& \\
\hline The Potential Risks daily routines \\
\hline
\end{tabular}

1. Privacy and security

2. Reliability

3. Satisfaction

4. Trust on device controlling.

\section{Conceptual model}

The previous reviews and the author's findings support the conceptual model in this study. The following graph depicts the study's conceptual model and, essentially, the researcher's perspective. The "smart city" concept, according to scientists like Carlo Carpa, consists of six components, each of which is composed of several theories and features (Table 2). Smart living, among these different indicators, aims to improve the quality of life idea. And its features include education, culture and health, facilities, safety, housing, social cohesion, and tourist attractions. This research aims to analyze smart living and especially the social barriers of smart homes. In this regard, previous studies identified several factors as the most significant social issues of residents. These criteria include privacy, security, reliability, satisfaction, and device control. Finally, the author of this article selects these factors as criteria for assessing residents' satisfaction with living in smart homes. Figure 1 describes the conceptual model in detail.

\section{Case study}

This paper needs to examine its set indicators in a case study to achieve the research objectives. For this purpose, four European cities (Copenhagen, Berlin, Barcelona, and London) are selected as the case studies. It is worth noting that this paper aims to recognize the social barriers based on resident's experience in smart homes. The author defines four criteria to measure the social issues, then conducts interviews with residents to assess the effect of these criteria. Finally, based on the residents' comments, the significant social barriers of smart homes are identified.

In 2018, the Eden Strategy Institute ranked smart cities in the globe base on multiple criteria. This study rate

Table 6 Social barriers presented in articles

\begin{tabular}{ll}
\hline Essay & Social barriers \\
\hline Insights on Smart Home concept and occupants' interaction with building controls [37]. & $\bullet$ Retrofitting of existing homes \\
& $\bullet$ Interoperability \\
& $\bullet$ Reliability \\
& $\bullet$ Usability and security \\
Smart homes and their users: a systematic analysis and key challenges [38]. & $\bullet$ Privacy \\
Social barriers to the adoption of smart homes [25]. & $\bullet$ Control \\
& $\bullet$ Fit to the current and changing lifestyles \\
& $\bullet$ Administration \\
& $\bullet$ Interoperability \\
& $\bullet$ Reliability \\
& $\bullet$ Privacy and security \\
\hline
\end{tabular}




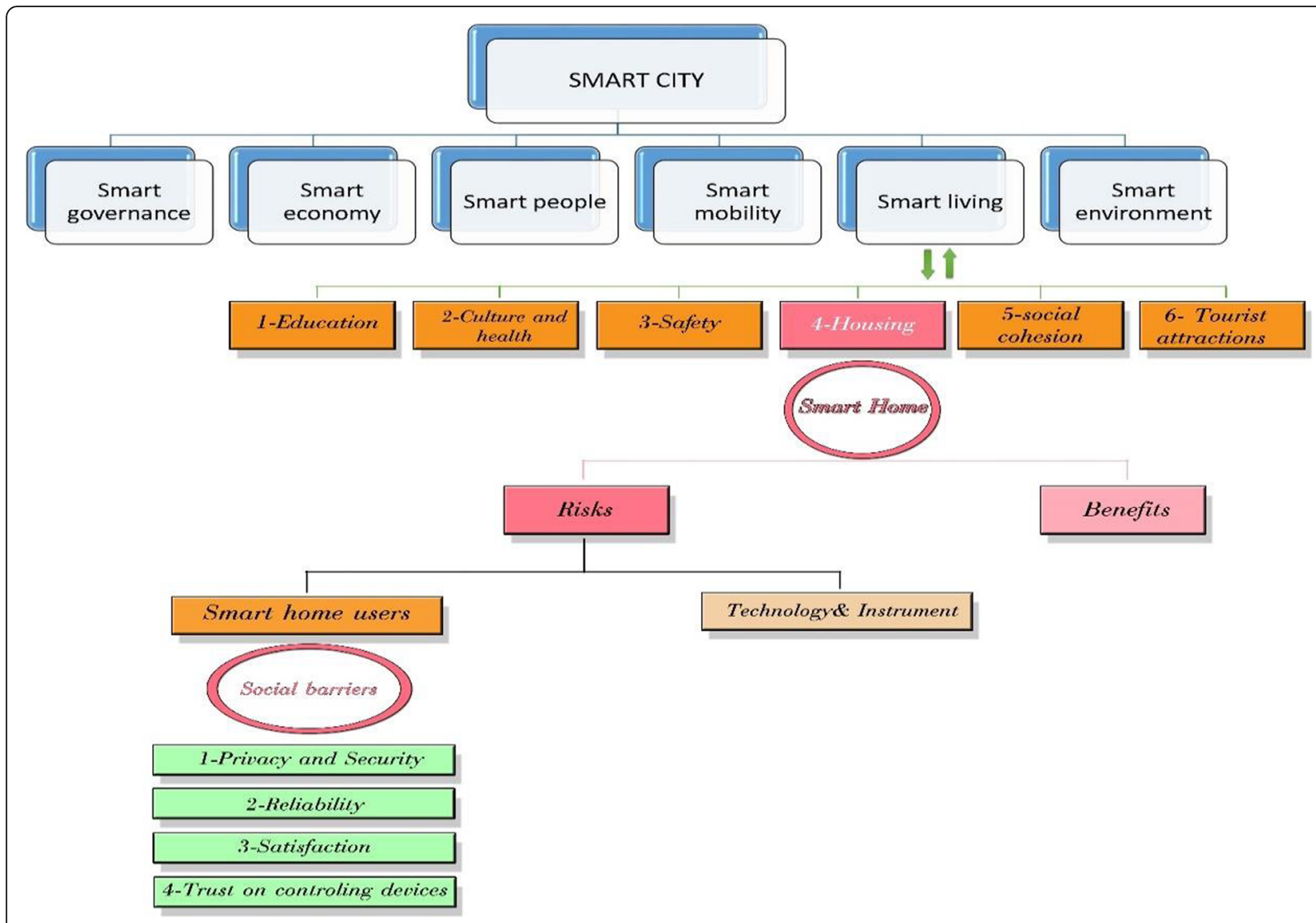

Fig. 1 Conceptual model. Source "by the author"

50 smart cities across the globe. The Berlin city is rated 29th in the report, Copenhagen 24th, Barcelona 9th, and London 1st. In this article, the researcher chose 4 European cities. Each of these countries made significant strides as a leader in the smart city concept. While residents are willing to embrace state-of-the-art technologies, several issues have created obstacles among these residents. The questionnaires will help evaluate the components after choosing the case studies to answers the research questions.
To accurately analyze these four components, a group of experts from various fields identified several subcomponents. The group includes seven experts in the fields of urban planning, regional planning, urban design, and architecture. Also, these experts have extensive expertise in the area of urban planning and management. Table 7 is a list of the expert group criteria.

Table 8 presents the indicators and sub-indicators analyzed in this study. The author addresses these variables in the questionnaire questions.

Table $\mathbf{7}$ Introducing the characteristics of experts and their field of activity

\begin{tabular}{lllll}
\hline & University degree & Field of academic Study & Field of activity & Professional work experience (year) \\
\hline Expert number 1 & Master & Urban planning & Urban engineering company & 8 years \\
Expert number 2 & Master & Urban design & Urban engineering company & 14 years \\
Expert number 3 & $\mathrm{PhD}$ & Architecture & University faculty member & 7 years \\
Expert number 4 & Bachelor & Architecture & Urban engineering company & 5 years \\
Expert number 5 & $\mathrm{PhD}$ & Urban and regional planning & University faculty member & 9 years \\
Expert number 6 & PhD & Urban planning & University faculty member & 5 years \\
Expert number 7 & Master & Urban design & Urban engineering company & 15 years \\
\hline
\end{tabular}


Table 8 Components and sub-components of the social problems in the smart home

\begin{tabular}{ll}
\hline Indicators & Sub-indicators \\
\hline 1- Privacy and security & - Smart systems for surveillance \\
2- Reliability & - Smart system for detection \\
& - Smart system for identification \\
3- Satisfaction & - Smart system for forecasting emergencies \\
& - smart system for environmental situations \\
& - smart system for remote control devices \\
& - Privacy protection \\
& - Safe internet connection \\
4- Trust on controlling devices & - Reducing energy consumption \\
& - Saving time \\
& - Reduce the cost of housing construction \\
& - Easier access to services \\
& - Better education \\
& - Increasing the health of residents \\
& - Operation of different devices with each other \\
& - Owners ability to change smart device settings
\end{tabular}

The questions in the questionnaire comprise subcomponents determined by the expert group. In this way, we will identify the social issues that trigger dissatisfaction among smart home residents. The questionnaire is composed of two parts. Part one contains sociodemographic questions (age of respondent, the gender of the respondent, profession, household income) and a specific question regarding smart homeowners' academic studies. The screening question seeks to find the best people's responses to the assessment. The screening query was "What are digital home technologies?" Options of response range from "no idea," "primeval information," and "good Information." Respondents who replied "no idea" removed in this part. We will need residents who are knowledgeable regarding smart appliances to find the research goal. To this end, the research did not analyze the views of those who believed they lacked expertise in this field. The next section of the survey begins with an open-ended question asking respondents to give a few phrases about "What first comes to mind when you think of smart home technologies?" This question allows us to get a deeper understanding of how respondents think about smart home technology. Finally, the researcher assessed the interviewees' opinions, and the responses were graded in the range 1 to 10 to evaluate each sub-indicator.

The research gathers primary data from 320 smart homeowners through random-cluster sampling via the adoption of a questionnaire study. So the researcher filled out 80 questionnaires at each sample city. The selection of interviewees is a crucial part of this research. Smart homeowners living in houses fitted with the latest technology are the interviewees in this study. Accordingly, the research group distributed the questionnaires to residents of the smart home in the four cities surveyed. Researchers select 80 residents of smart homes in each of those four cities. The investigator identified these families by associates in each of these cities. He contacted them and explained the goal of this study, and sent the questionnaire to them. To receive diverse viewpoints, the researcher chose interviewers with different characteristics. The characteristics of the people who filled out the questionnaires illustrate in Table 9. It should mention that the author emailed the questionnaires to identified people due to the dispersion of the case studies. Then, the interviewees sent the completed questionnaires to the researcher.

The author picked the respondents from different age groups and genders as well as various social groups. The following tables provide some information about all 320 interviewees. Also, Fig. 2 presents the gender distribution:

Table 10 shows the number and percentage of respondents by age group.

The details of the interviewees' academic rate are set out in Table 11

The author of this study explores four metrics as criteria for measuring social issues within smart home residents. The following graph depicts residents' concerns regarding smart homes in four cities. The least concerning factor of these four indicators, according to the interviewees, was privacy and security. This measure has the highest percentage, meaning that residents are the most satisfied with it. In contrast, they

Table 9 Information about the respondents to the questionnaires

\begin{tabular}{lllll}
\hline & London (England) & Berlin (Germany) & Copenhagen (Denmark) & Barcelona (Spain) \\
\hline Interviewees & 80 & 80 & 80 & 80 \\
\hline
\end{tabular}




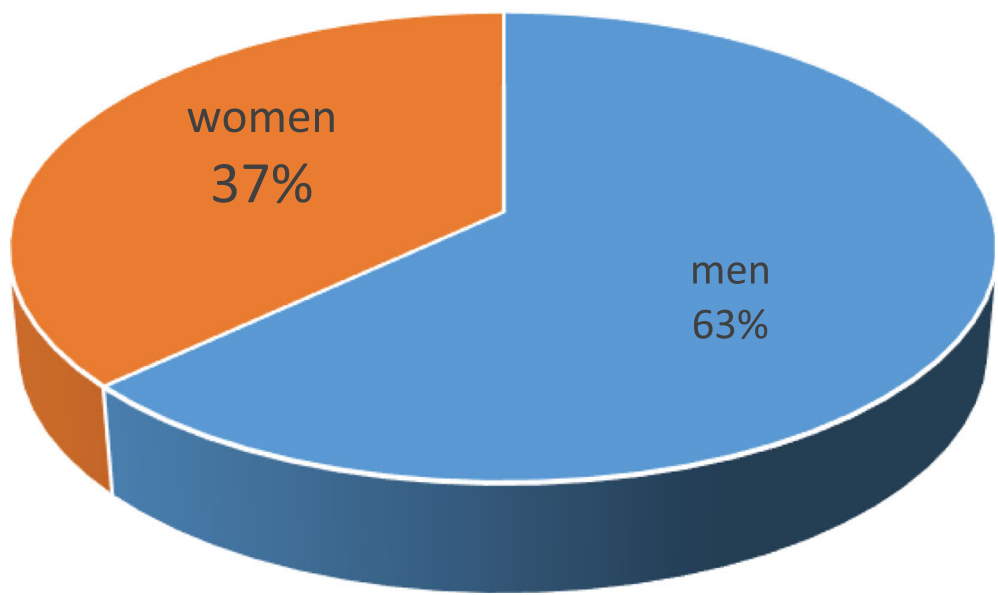

Fig. 2 The distribution of respondents by gender. Source "by the author"

state that their significant concern is trust in controlling devices (Fig. 3).

The bar figure below illustrates each city's score depending on the chosen measures. The city with the highest score is Copenhagen, while London has the lowest score. On the other hand, the two cities of Berlin and Barcelona also rank second and third respectively. It is worth noting that the lower a city's ratings, the less effective it is in terms of social concerns, and residents face more social issues.

Copenhagen placed in the fifth position based on the world's happiest cities in the World Happiness Report (WHR) 2020. The satisfaction of citizens living in this country is at a very high level. The survey included criteria such as life expectancy, security, and satisfaction with living in cities, which indicates a high level of quality of life in this city. On the other hand, in this research, the author aimed to make sure that the resident's satisfaction in different cities does not affect how they react to the questionnaire. And only their concerns about the social factors mentioned in the questionnaire should analyze. Instead of dwelling on whether or not they are happy with living in their cities, the questionnaire focuses on the most significant social obstacles they face in their smart homes (Fig. 4).

Table 10 The number and percentage of respondents by age group

\begin{tabular}{lll}
\hline & Numbers & Percentage \\
\hline 25 years and less & 60 & 18.8 \\
Between 25 and 35 years & 98 & 30.6 \\
Between 35 and 45 years & 77 & 24.1 \\
Between 45 and 55 years & 65 & 20.3 \\
Over 55 years & 20 & 6.3 \\
Total & 320 & 100 \\
\hline
\end{tabular}

Source "by the author"
The bar figure below illustrates the scores for each indicator in 4 cities. Each indicator's value was determined using a 1 to 10 ratio. It means that the higher a criterion's indicator score is, the less worried residents are about it. Overall, Copenhagen outperformed the other three cities in each of these measures. Another point to remember is the low level of confidence in control devices. The privacy and security parameter, on the other hand, was the least troubling indicator. The following sections go into the details of each city's situation:

Copenhagen: The "privacy and security" component in this city has the lowest level of concern among the smart home's residents. Also, they state that "trust in controlling devices" is the significant troublesome among the indicators analyzed in this research. Also, the other two components are in a better position. Berlin: "Privacy and security" in this city have a lower score than in Copenhagen. However, this component has more favorable conditions than the other two cities. In this city, "trust in controlling devices" has the lowest level of satisfaction among respondents.

Barcelona: The equality of the scores of the two components-"privacy and security" and "reliability"-is a significant point in this city. As a result, these two components have the highest level of satisfaction.

Table 11 The number and percentage of participants according to the level of education

\begin{tabular}{lll}
\hline & Numbers & Percentage \\
\hline No academic education & 10 & 3.1 \\
Bachelor degree & 123 & 38.4 \\
Master degree & 157 & 49.1 \\
Ph.D. degree & 30 & 9.4 \\
Total & 320 & 100 \\
\hline
\end{tabular}

Source "by the author" 


\section{THE CONTRIBUTION OF EACH SOCIAL BARRIERS IN SMART HOME}

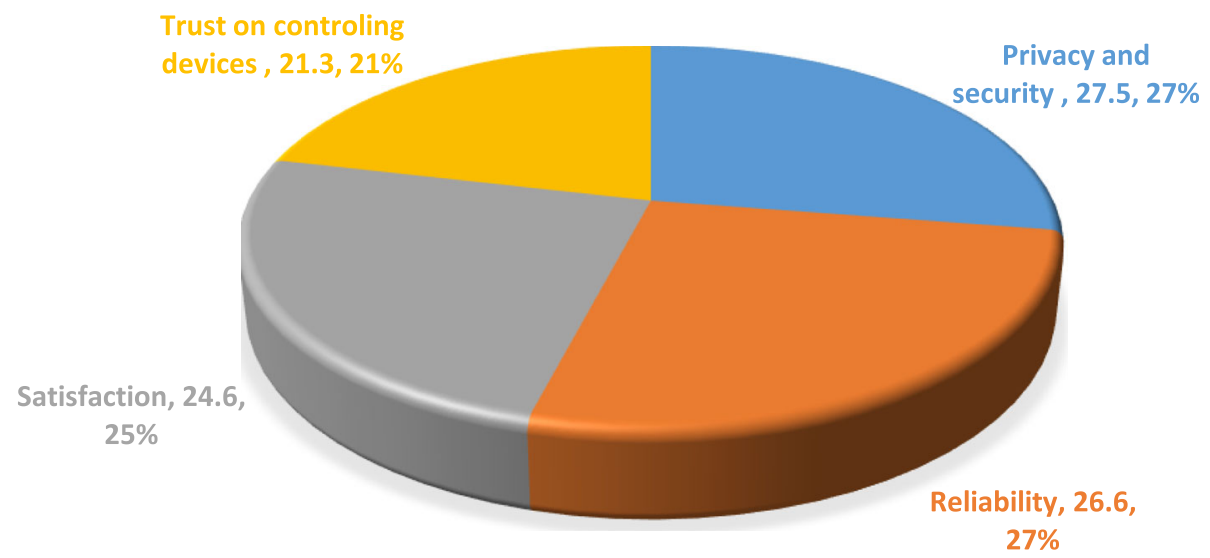

Fig. 3 The contribution of each social barriers in smart home. Source "by the author"

While "trust in controlling devices" has the lowest level of residents' satisfaction.

London: The point that clear in this city is that almost all the components scored fewer points than the other three cities. Also, the residents' satisfaction trend in this research is similar to the other three examples. As a result, the highest level of satisfaction is associated with "privacy and security," while the lowest level of satisfaction is related to "trust in controlling devices" (Fig. 5).

The author appropriates several sub-components in this research for an accurate analysis of the components. These sub-components are the result of discussion and consultation obtained from the expert group. The conclusions derived from the sub-component analysis illustrates in the following diagram (Fig. 6).

Table 12 represents the scores of the sub-component by city. Furthermore, a separate column shows the average score of each component. Based on the average scores, the "privacy and security" component has the highest score (8.4), therefore has the highest level of satisfaction among smart home residents. In contrast, "trust in controlling devices" has the lowest score (6.4), reflecting resident frustration with smart homes. It is worth noting that among all the sub-components, "smart surveillance systems" with a score of 9.5 have the highest level of satisfaction in Copenhagen. In contrast, several sub-criteria in the two "satisfaction" and "trust on controlling devices" criteria scored the lowest.

\section{The scores of each city based on the criteria}

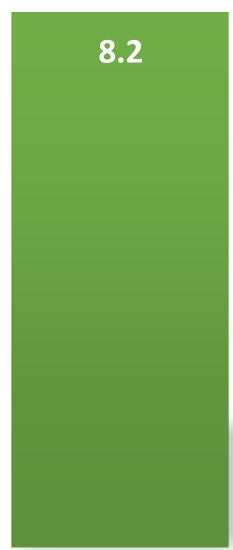

Copenhagen

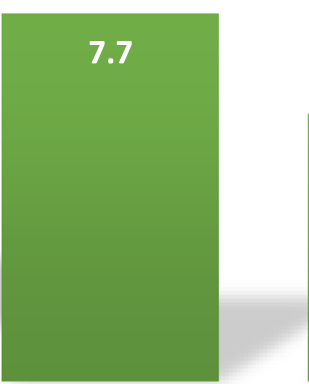

Berlin

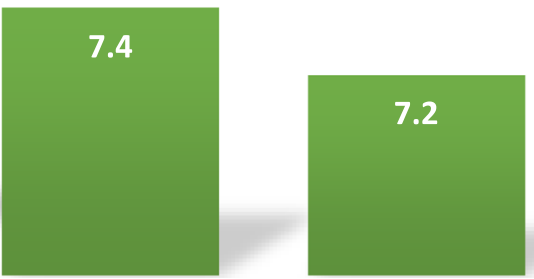

Barcelona

London

Fig. 4 The scores of each city based on the criteria. Source "by the author" 


\section{Criteria scores of social problems by city}

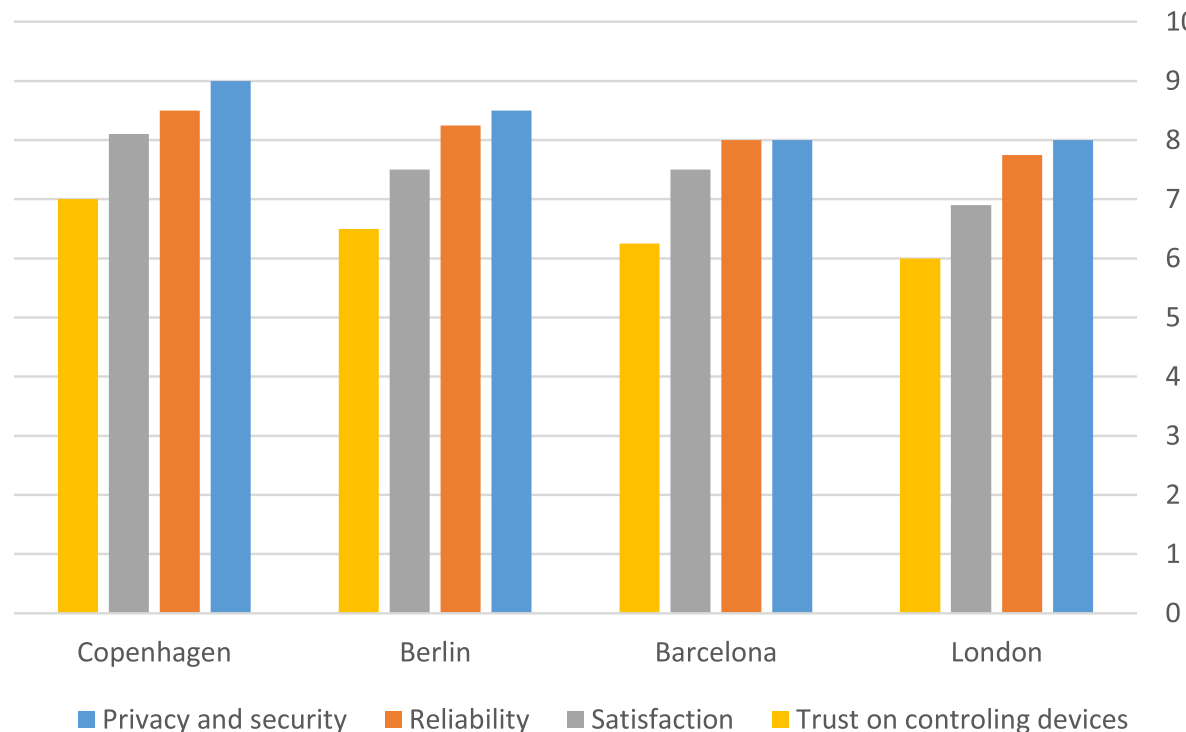

Fig. 5 Criteria scores of social problems by city. Source "by the author"

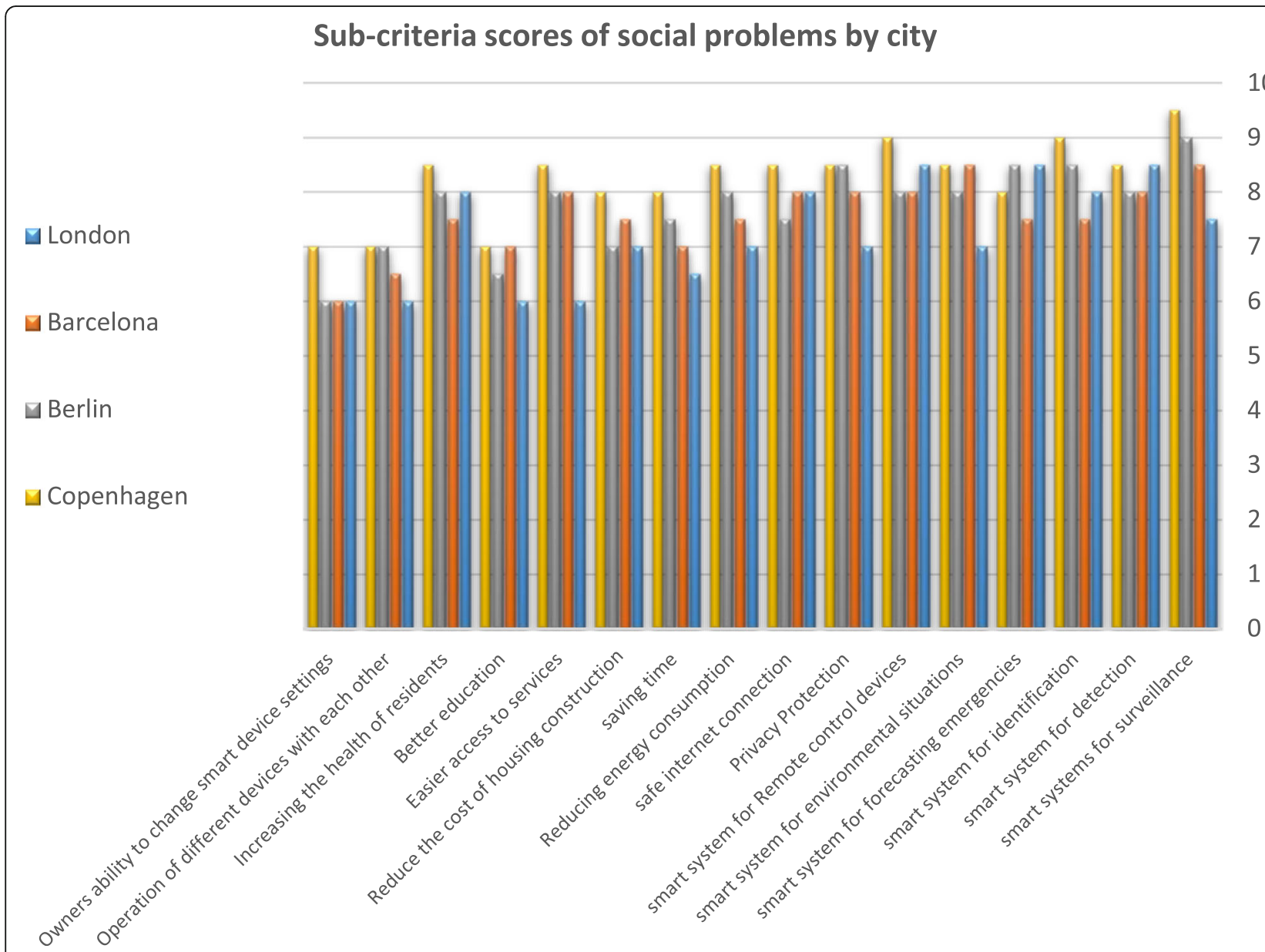

Fig. 6 Sub-criteria scores of social problems by city. Source "by the author" 
Table 12 The average rating of each of the criteria and sub-criteria

\begin{tabular}{|c|c|c|c|c|c|c|}
\hline Average & Copenhagen & Berlin & Barcelona & London & Sub-criteria & Criteria \\
\hline \multirow[t]{3}{*}{8.4} & 9.5 & 9 & 8.5 & 7.5 & Smart systems for surveillance & Privacy and security \\
\hline & 8.5 & 8 & 8 & 8.5 & Smart system for detection & \\
\hline & 9 & 8.5 & 7.5 & 8 & Smart system for identification & \\
\hline \multirow[t]{4}{*}{8.1} & 8 & 8.5 & 7.5 & 8.5 & Smart system for forecasting emergencies & Reliability \\
\hline & 8.5 & 8 & 8.5 & 7 & Smart system for environmental situations & \\
\hline & 9 & 8 & 8 & 8.5 & Smart system for Remote control devices & \\
\hline & 8.5 & 8.5 & 8 & 7 & Privacy protection & \\
\hline \multirow[t]{7}{*}{7.5} & 8.5 & 7.5 & 8 & 8 & Safe internet connection & Satisfaction \\
\hline & 8.5 & 8 & 7.5 & 7 & Reducing energy consumption & \\
\hline & 8 & 7.5 & 7 & 6.5 & Saving time & \\
\hline & 8 & 7 & 7.5 & 7 & Reduce the cost of housing construction & \\
\hline & 8.5 & 8 & 8 & 6 & Easier access to services & \\
\hline & 7 & 6.5 & 7 & 6 & Better education & \\
\hline & 8.5 & 8 & 7.5 & 8 & Increasing the health of residents & \\
\hline \multirow[t]{2}{*}{6.4} & 7 & 7 & 6.5 & 6 & Operation of different devices with each other & Trust on controlling device \\
\hline & 7 & 6 & 6 & 6 & Owners ability to change smart device settings & \\
\hline
\end{tabular}

Source "by the author"

According to interviews findings in Copenhagen, the reason for their high level of satisfaction is the government's monitoring of smart surveillance systems. In other words, government agencies' oversight of the nongovernmental service providers has increased public satisfaction. On the other hand, some residents in the other three cities are dissatisfied with the smart services provided by private and public companies. They suppose that the operation of several smart devices at the same time will cause issues due to the lack of monitoring of these systems.

\section{Conclusion}

According to smart home definitions, scientists state that such houses seek to utilize up-to-date technologies such as the internet to create more beneficial homes. It is important to consider that smart homes aim to improve the inhabitants' quality of life besides their satisfaction. The advantages of designing smart homes are increasing economic growth, security, time savings, and pollution mitigation. On the other hand, the utilization of such services raises multiple challenges and concerns. One of the obstacles is the residents' satisfaction with the use of these services. For instance, dependency on the Internet, interference in people's privacy, and high expense of accessing such services. The most significant purpose of this article is to analyze the social issues of smart home residents. The primary goal is to identify such barriers. Also, what is the most significant social obstacles for residents? The most concerning social barriers describe below according to the case studies findings.

1- Trust on controlling devices.

2- Service satisfaction.

3- The reliability of the services.

4- Privacy and security.

According to interviews, the most significant issue is related to devise management. Respondents are concerned about how several devices operate simultaneously. To prevent such disorders, control officials must supervise the accurate performance of each of these smart devices. Also, experts should perform experiments to examine how multiple devices interact at the same time to identify potential troubles. This surveillance would improve consumer's trust and lead to the increased utilization of these technologies in non-smart homes. Besides, companies should have periodic checkups to inspect the equipment to resolve any new issues. Eventually, through these approaches, citizens' services improved to offer people satisfaction with smart home services. The last section provides the most significant recommendations to mitigate the challenges and facilitate the safe and effective use of smart home applications.

\section{User recommendations}

Home energy services are primarily responsible for appliance power consumption data, performing energy 
efficiency assessments of household appliances, and making recommendations about household power consumption. The technology-based systems present recommendations for users to reduce energy consumption. A device provides suggestions for mobile users when an intruder is detected. To decrease power consumption and the cost of household appliances efficiently, we recommend that users commit to the set runtime.

\section{Health recommendations}

Health institutions are primarily responsible for assisting and ensuring high-quality medical applications in smart homes and healthcare in general. Health institutions support the elderly (at home) by providing correct instructions, such as appropriate exercises through TV tutorials. Recommendations are given to patients in smart homes, including medical guidelines, patient diagnoses, and assistance for the elderly and people with disabilities. Such technologies can also determine and predict unexpected incidents such as fall injuries in smart homes.

\section{Safety recommendations}

Another advantage of using technology-based devices in smart homes is increased safety. People of all ages require specific healthcare, especially the elderly, and children often need guidance and help from those around them. Using a monitoring system provides appropriate supervision for homeowners if they are not at home. Also, ensuring that strangers do not enter smart homes are other benefits of using these homes. As a result, homes equipped with these applications will bring higher satisfaction to homeowners. Furthermore, smart devices provide instructions on how fire systems and electrical appliances are utilized and managed. A recommendation system to manage IoT-network relationships between IoT devices, networks, and operation techniques helps implement appropriate schemes, diagnose errors in smart homes.

\section{Limitations}

The most crucial section in this research was designing the questionnaire and assessing questionnaire data. Several experts evaluated the questionnaire indicators, then sub-criteria were identified for a more detailed study. It should note that this process was very time-consuming. Another obstacle in this research was finding informed people about smart homes to fill out the questionnaire. To sum up, smart home technologies face serious challenges. Further study and practical solutions to address the problems that lay ahead would pave the way for such technologies extension.

\section{Acknowledgements}

I would like to express my very great appreciation to my professor for his valuable and constructive suggestions during the planning and development of this research work. His willingness to give his time so generously has been very much appreciated.

\section{Author's contributions}

The author has collaboratively contributed to all phases of the research and in the development of the manuscript. The author(s) read and approved the final manuscript.

\section{Funding}

This research did not receive any specific grant from funding agencies in the public, commercial, or not-for-profit sectors.

Availability of data and materials

All sources of data and materials analyzed in the course of this paper a listed in the reference section.

\section{Declarations}

Ethics approval and consent to participate

Not applicable

Consent for publication

Not applicable

Competing interests

The author declares no competing interests.

Received: 11 April 2019 Accepted: 13 April 2021

Published online: 06 May 2021

\section{References}

1. United Nations Human Settlements Programme (2011) Cities and climate change: global report on human settlements, 2011. Routledge

2. Bibri SE, Krogstie J (2017) Smart sustainable cities of the future: an extensive interdisciplinary literature review. Sustain Cities Soc 31:183-212

3. Nam T, Pardo TA (2011) Conceptualizing smart cities with dimensions of technology, people, and institutions. In: Proceedings of the 12th annual international digital government research conference: digital government innovation in challenging times, pp 282-291 ACM

4. Ibrahim M, El-Zaart A, Adams C (2018) Smart sustainable cities roadmap: readiness for transformation towards urban sustainability. Sustain Cities Soc 37:530-540

5. Ishida T, Isbister, K. (Eds.). (2000) Digital cities: technologies, experiences, and future perspectives. Springer Science \& Business Media

6. Bifulco F, Tregua M, Amitrano CC, D'Auria A (2016) ICT and sustainability in smart cities management. Int J Public Sector Manage 29(2):132-147

7. Anthopoulos LG, Tougountzoglou TE (2012) A viability model for digital cities: economic and acceptability factors. In: Web 2.0 Technologies and Democratic Governance. Springer, New York, pp 79-96

8. Hollands RG (2008) Will the real smart city please stand up? Intelligent, progressive, or entrepreneurial? City 12(3):303-320

9. Dameri RP, Cocchia A (2013) Smart city and digital city: twenty years of terminology evolution. In: X Conference of the Italian Chapter of AIS, ITAIS, pp 1-8

10. Neirotti P, De Marco A, Cagliano AC, Mangano G, Scorrano F (2014) Current trends in smart city initiatives: some stylized facts. Cities 38:25-36

11. Jucevičius R, Patašienè I, Patašius M (2014) Digital dimension of a smart city: a critical analysis. Procedia-Soc Behav Sci 156:146-150

12. Caragliu A, Del Bo C, Nijkamp P (2011) Smart cities in Europe. J Urban Technol 18(2):65-82

13. Schaffers $H$, Komninos $N$, Pallot $M$, Trousse B, Nilsson M, Oliveira A (2011) Smart cities and the future internet: towards cooperation frameworks for open innovation. In: The future internet assembly. Springer, Berlin, pp 431-446

14. Capra CF (2016) The smart city and its citizens: governance and citizen participation in Amsterdam Smart City. Int J E-Plan Res (IJEPR) 5(1):20-38

15. Shapiro JM (2006) Smart cities: quality of life, productivity, and the growth effects of human capital. Rev Econ Stat 88(2):324-335 
16. Florida R (2003) Cities and the creative class. City Community 2(1):3-19

17. Campbell T (2012) Beyond smart city: how cities network, learn and innovate. Earthscan, New York

18. Moretti, E. (2013). The new geography of work. Mondadori Editions.

19. Lindskog H (2004) Smart communities initiatives. In: Proceedings of the 3rd ISOneWorld Conference, vol 16, pp 14-16

20. High, P. (2015). The top five smart cities in the world. Forbes. com.

21. AlDairi A (2017) Cybersecurity attacks on smart cities and associated mobile technologies. Procedia Comp Sci 109:1086-1091

22. Marikyan D, Papagiannidis S, Alamanos E (2019) A systematic review of the smart home literature: a user perspective. Technol Forecasting Soc Change 138:139-154

23. Aldrich FK (2003) Smart homes: past, present, and future. In: Inside the smart home. Springer, London, pp 17-39

24. Lutolf $R$ (1992) Smart home concept and the integration of energy meters into a home-based system. In: Seventh International Conference on Metering Apparatus and Tariffs for Electricity Supply, pp 277-278 IET

25. Balta-Ozkan N, Davidson R, Bicket M, Whitmarsh L (2013) Social barriers to the adoption of smart homes. Energy Policy 63:363-374

26. Li M, Gu W, Chen W, He Y, Wu Y, Zhang Y (2018) Smart home: architecture, technologies, and systems. Procedia Comp Sci 131:393-400

27. Khan Z, Anjum A, Kiani SL (2013) Cloud based big data analytics for smart future cities. In: 2013 IEEE/ACM 6th International Conference on Utility and Cloud Computing, pp 381-386 IEEE

28. Michalik P, Štofa J, Zolotova I (2014) Concept definition for Big Data architecture in the education system. In: 2014 IEEE 12th International Symposium on Applied Machine Intelligence and Informatics (SAMI), pp 331-334 IEEE

29. Pantelis K, Aija L (2013) Understanding the value of (big) data. In: 2013 IEEE International Conference on Big Data, pp 38-42 IEEE

30. Tantatsanawong P, Kawtrakul A, Lertwipatrakul W (2011) Enabling future education with smart services. In: 2011 Annual SRII Global Conference, pp 550-556 IEEE

31. Galán-García JL, Aguilera-Venegas G, Rodríguez-Cielos P (2014) An accelerated-time simulation for traffic flow in a smart city. J Comput Appl Math 270:557-563

32. U.S. Department of Energy, "Smart Grid / Department of Energy," Web: http://www.energy.gov/oe/technology-development/smart-grid, Retrieved Sep. 23, 2015.

33. Fan W, Bifet A (2013) Mining big data: current status, and forecast to the future. ACM SIGKDD Explor Newsl 14(2):1-5

34. Al Nuaimi E, Al Neyadi H, Mohamed N, Al-Jaroodi J (2015) Applications of big data to smart cities. J Internet Serv Appl 6(1):1-15

35. Plan SET (2015) Towards an integrated strategic energy technology (set) plan: accelerating the European energy system transformation. C 2015:6317

36. Wilson C, Hargreaves T, Hauxwell-Baldwin R (2017) Benefits and risks of smart home technologies. Energy Policy 103:72-83

37. Fabi V, Spigliantini G, Corgnati SP (2017) Insights on smart home concept and occupants' interaction with building controls. Energy Procedia 111:759-769

38. Wilson C, Hargreaves T, Hauxwell-Baldwin R (2015) Smart homes and their users: a systematic analysis and key challenges. Personal Ubiquitous Comp 19(2):463-476

\section{Publisher's Note}

Springer Nature remains neutral with regard to jurisdictional claims in published maps and institutional affiliations.

\section{Submit your manuscript to a SpringerOpen ${ }^{\circ}$ journal and benefit from:}

- Convenient online submission

- Rigorous peer review

- Open access: articles freely available online

High visibility within the field

- Retaining the copyright to your article

Submit your next manuscript at $\boldsymbol{\nabla}$ springeropen.com 